\title{
P01-017 - FMF presention with features of malignancy
}

\author{
N Aktay Ayaz ${ }^{1 *}$, G Keskindemirci $^{1}$, D Tugcu², A Akçay ${ }^{3}$, E Aldemir $^{1}$, G Aydogan $^{1}$ \\ From 7th Congress of International Society of Systemic Auto-Inflammatory Diseases (ISSAID) \\ Lausanne, Switerland. 22-26 May 2013
}

\section{Introduction}

Familial Mediterranean fever (FMF) is an autoinflammatory disease characterized by periodic attacks of fever and serositis caused by mutations in FMF gene (MEFV). Splenomegaly and lymphadenopathy has been reported in FMF. The abdominal lymphadenopahy was reported in the mesentery during laparotomies for acute abdominal attacks of FMF.

\section{Case Report}

A 14 year-old girl was admitted to the hospital with the complaints of fever, fatique and weight loss of $12 \mathrm{~kg}$ in 2 months duration. She had been prescribed different antibitiocis for fever. Her laboratory work-up was as follows; Hb. $7.4 \mathrm{gr} / \mathrm{dl}$, Hct $23 \%$, wbc $6000 / \mathrm{mm}^{3}$, Plt $231000 / \mathrm{mm}^{3}$, ESR: $112 \mathrm{~mm} / \mathrm{hr}, \mathrm{C}$-reactive protein: $52 \mathrm{mg} / \mathrm{l}$, differential count and bone marrow aspiration was normal. Vitamin B12 level was low. Autoantibodies and microbiological work-up were unremarkable. She had hyperglobulinemia. Abdominal ultrasound revealed mild hepatosplenomegaly, but this was not noticed at physical examination. Pericardial effusion of $7 \mathrm{~mm}$ was present at echocardiography. Abdominal MRI revealed lymphadenopathy at paraaortic region and and splenic hilus. Positron emission tomography was performed and increased fdg involvement at paraaortic, splenic and hepatic region, hypermetabolism at malignancy level and hypermetabolism in the spleen were detected. With the possible diagnosis of lymphoproliferative disease involving the spleen, an excisional biopsy was planned. During evaluation, the patient developed arthritis at her wrists. Due to the presence of fever, pericardial effusion, splenomegaly, arthritis and high inflammatory markers; MEFV mutation analysis was done. But in a month time, she lost 5 more $\mathrm{kg}$, so a laparatomy and excisional biopsy was performed. Histopathology revealed only reactive lymphadenopathy without any malignant infiltration. She was found to be homozygous for M694V mutation. Colchicine treatment was introduced and nearly in a month time her ESR level decreased to $50 \mathrm{~mm} / \mathrm{hr}$ and she had started to gain weight. In the next month's visit all of her complaints were gone and ESR had become normal. She is still under colchicine treatment without any complication for 3 months.

\section{Discussion}

This is a very interesting FMF case presenting with the symptoms of malignancy and we were obliged to have a biopsy in order to exclude malignancy. In the literature there are few reports about such severe cases involving abdominal lymph nodes. This case is presented due to its unusual severe presentation and excellent response in 2 months time to colchicine.

\section{Disclosure of interest}

None declared.

\section{Authors' details}

${ }^{1}$ Pediatric Rheumatology, Istanbul Kanuni Sultan Suleyman Education and Research Hospital, Istanbul, Turkey. ${ }^{2}$ Pediatric Oncology, Istanbul Kanuni Sultan Suleyman Education and Research Hospital, Istanbul, Turkey. ${ }^{3}$ Pediatric Hematology, Istanbul Kanuni Sultan Suleyman Education and Research Hospital, Istanbul, Turkey.

Published: 8 November 2013

doi:10.1186/1546-0096-11-S1-A21

Cite this article as: Ayaz et al: P01-017 - FMF presention with features of malignancy. Pediatric Rheumatology 2013 11(Suppl 1):A21.

Pediatric Rheumatology, Istanbul Kanuni Sultan Suleyman Education and Research Hospital, Istanbul, Turkey

Full list of author information is available at the end of the article

(C) 2013 Ayaz et al; licensee BioMed Central Ltd. This is an Open Access article distributed under the terms of the Creative Commons 